\title{
Four-year review of admissions to a South African regional hospital general surgery department
}

\author{
J Pape, MB ChB; O Swart, MB ChB, FCS (SA); R Duvenage, MB ChB, MMed (Surgery) \\ Department of Surgery, Worcester Hospital and Ukwanda Centre for Rural Health, Stellenbosch University, Cape Town, South Africa
}

Corresponding author: J Pape (drjamespape@gmail.com)

\begin{abstract}
Background. There are limited published data describing surgical admissions at a regional hospital level in the South African (SA) context. Objectives. To retrospectively review data from an electronic discharge summary database at a regional SA hospital from 2012 to 2016 to describe the burden of surgical disease by analysing characteristics of the patients admitted.

Methods. All discharge summary records for the 4-year period were reviewed after extraction from a database created for the surgery department. Admissions were classified into 5 types: (i) elective surgery or investigations (ESI); (ii) trauma; (iii) burns; (iv) non-traumatic surgical emergencies (NTSE); and $(v)$ unplanned readmission within 30 days. Other variables reviewed were demographic data, the International Statistical Classification of Diseases and Related Health Problems - Version 10 (ICD-10) diagnosis; area of origin; and outcome (death, tertiary referral, discharge). Data were subgrouped into 12-month periods to facilitate trend analysis.

Results. Discharge summaries ( $N=9805)$ over the 4 -year study period were assessed and 9799 were included in the analysis. All data were entered by the attending medical personnel. A total of 5647 male patients (57.6\%) and 4152 female patients (42.4\%) were admitted, with a mean age of 43.3 years (95\% confidence interval (CI) 43.0 - 43.8) and a mean length of stay of 4.9 days (95\% CI 4.7 - 5.1). Male patients comprised a larger proportion of trauma (83.7\%) and burn (63.9\%) admissions. The mean length of stay ranged from 3.5 days for elective patients to 9.1 days for burn patients. The most common diagnoses for emergency admissions were appendicitis, peripheral vascular disease and peptic ulcer disease. Common diagnoses for elective admissions were gallstone disease, inguinal hernia, anal fistulas/fissures, and ventral and incisional hernia. The most common cancer diagnoses were of the colorectum, oesophagus, breast and stomach. The overall mortality rate was $2.2 \%$, and highest by subtype was burn patients $(6.3 \%)$. Trend analysis showed a statistically significant increase in admission for NTSE $(p=0.019)$, trauma $(p<0.001)$ and 30 -day readmission rates $(p<0.001)$, with a decrease in admissions for ESI $(p=0.001)$ over the 4 years.

Conclusions. A precise understanding of the burden of disease profile is essential for national, provincial and district budgeting and resource allocation. Ongoing surveillance such as that performed in the study provides this critical information.
\end{abstract}

S Afr Med J 2019;109(2):122-126. DOI:10.7196/SAMJ.2019.v109i2.13433

There are limited published data describing the nature of surgical admissions at a regional hospital level in the South African (SA) context. A literature search (most recently conducted on 16 July 2018) returned no published studies evaluating surgical admissions at a regional level in SA.

Data are available for trauma, burns and specific conditions. ${ }^{[1,2]}$ There is also a lack of data published globally that describes the disease burden of surgical emergencies. ${ }^{[3]}$ Surgical epidemiological research from other continents at a regional hospital level is usually based on operative data. ${ }^{[4]}$ Collecting data of all patients admitted at a surgical service correlates more closely with hospital capacity, as not all patients undergo surgery at each admission.

The SA healthcare system consists of a public sector serving $84 \%$ of the population, and a private sector that treats the remaining $16 \%,{ }^{[5]}$ but uses $45 \%$ of the country's overall healthcare expenditure to do so. ${ }^{[6]}$

Care in the government sector is provided at academic, regional and district levels. Academic and regional hospital surgical departments are generally staffed with subspecialist surgeons and general surgeons, respectively. District clinic and health centre surgical care is delivered by non-surgeons (general practitioners or family medicine specialists), or by surgeons from larger facilities who visit occasionally where outreach programmes have been set up.

During apartheid, resources focused on urban and privileged areas, and in the post-apartheid era significant effort has been made to balance the system. The health department has attempted to restructure the service, leading to district hospitals and health centres being the primary delivery vehicle for healthcare. ${ }^{[7]} \mathrm{A}$ list has been published of surgical procedures that the District Hospital Service Package (DHSP) should include. ${ }^{[8]}$

Funding allocation has been adjusted away from academic facilities that have had to cut bed numbers and theatre lists. District-level facilities have received increased funding, but have been unable to expand their capacity to manage patients with surgical conditions designated for treatment there. It has been demonstrated that very limited acute general surgery, as defined in the DHSP list, is performed at district level. ${ }^{[9]}$ These patients often require referral to a regional hospital.

The combination of increased referrals from district hospitals and decreased capacity at academic facilities results in pressure on regional hospitals to deliver definitive surgical care to more patients. This strain is exacerbated by recent treasury budget restrictions and the consequent requirement for hospital management to save money.

The Lancet Commission on Global Surgery has established that $28-32 \%$ of the global burden of disease is estimated to be surgically treatable. ${ }^{[10]}$ Non-communicable disease has a mortality more than double that of infectious disease, malnutrition and maternal and perinatal disease combined. ${ }^{[11]}$ Despite this, surgery is not prioritised in healthcare planning and research in SA. As infectious disease management improves, the contribution of chronic illness is 
anticipated to assume a relatively greater proportion of the disease burden. Consequently, surgical illness is expected to become more prevalent in an ageing population, with increasing comorbidities, leading to longer inpatient stays and greater demand for critical care unit treatment.

The National Department of Health has acknowledged that improved access to safe surgery and anaesthesia is required, but have not yet published a plan for achieving this. ${ }^{[12]}$ High-quality surgical burden of disease data are essential to broaden an understanding of this problem and bring it to the attention of those involved in healthcare planning.

Worcester Hospital is a busy regional healthcare facility in the Western Cape Province, servicing the public sector of the Cape Winelands East and Overberg districts, which has a population of 638 671, according to the Statistics SA 2011 census. ${ }^{[13,14]}$ It has 4 high-care beds, 5 operating theatres and computed tomography (CT) scanning facilities available during weekdays. The surgery department maintains a detailed database of discharge summaries, which was reviewed with the aim of describing all admissions to general surgery over a 4-year period.

\section{Methods}

A retrospective review was undertaken of surgical admissions over 4 years from February 2012 to January 2016.

Data were extracted from a pre-existing electronic discharge summary database created for the surgery department. All patients admitted to the department were included and data entered by attending medical personnel to ensure accuracy. Admissions were classified into 5 types: (i) elective surgery or investigations (ESI); (ii) trauma; (iii) burns; (iv) non-traumatic surgical emergencies (NTSE); and ( $v$ ) unplanned readmission within 30 days.

Data were subgrouped into 12-month periods to facilitate trend analysis, which was done using a repeating $\chi^{2}$ with year 1 as reference - this was an unadjusted analysis.

Other variables included demographic data; the International Statistical Classification of Diseases and Related Health Problems - Version 10 (ICD-10) diagnosis; and length of stay and outcome (death, tertiary referral, discharge). The health department's policy is that all patients who die during admission or are referred to a tertiary centre have a discharge database entry created, facilitating analysis of mortality and referral rates.

Data were entered into Microsoft Excel (Microsoft, USA) and analysed on two separate occasions. Patient records that were incomplete or records with uninterpretable data were followed up to provide missing data and if still incomplete were excluded.

ICD-10 data for elective and emergency admissions were analysed and grouped by disease for analysis. Subcategories of the ICD-10 code were grouped in some instances for clarity. Readmissions within
$<30$ days were excluded from the disease frequency count to prevent duplication of data. ICD-10 data for trauma and burn patients were found not to be recorded accurately enough to be meaningful and were therefore excluded from frequency analysis. Diagnoses that included a proven malignancy were summed to provide a ranking of patients with the most common types of cancer.

\section{Ethical approval}

Ethical approval was obtained from Stellenbosch University's Health Research Ethics Committee (ref. no. N16/04/054) and the Western Cape Health Research Committee (ref. no. WC_2016RP38_635).

\section{Results}

Discharge summaries ( $N=9$ 805) over the 4-year study period were assessed and 9799 were included for analysis; 5647 male patients (57.6\%) and 4152 female patients (42.4\%) were admitted, with a mean age of 43.3 years ( $95 \%$ confidence interval (CI) 43.0 - 43.8) and a mean length of stay of 4.9 days (95\% CI 4.7 - 5.1).

Table 1 shows demographic data and length of stay of patients by admission type. Male patients were a larger proportion of trauma (83.7\%) and burn (63.9\%) admissions. Mean length of stay ranged from 3.5 days for elective patients to 9.1 days for burn patients.

The most common emergency admission diagnoses (Table 2) were appendicitis, followed by peripheral vascular disease and peptic ulcer disease. For ESI admissions (Table 3), gallstone disease was the most common, followed by inguinal hernia, anal fistulas and fissures, and ventral and incisional hernia.

Highest ranking admissions for cancer (Table 4) comprised colorectal, oesophagus, breast and stomach diagnoses.

Analysis was also undertaken of mortality and tertiary referral rates (Table 5). Mortality data related to death of an inpatient at our study hospital; data for deaths of patients referred to an academic centre were not available. The overall mortality rate was $2.2 \%$, and highest by subtype was burn patients (6.3\%). The elective patient mortality rate was $0.6 \% ; 9.1 \%$ of burn patients were referred to tertiary hospitals, and overall $2.3 \%$ of patients admitted were referred to a tertiary hospital.

Finally, the number of admissions for each type was represented per year over the 4-year period (Table 6). Trend analysis showed a statistically significant increase in admission for NTSE $(p=0.019)$, trauma $(p<0.001)$ and 30 -day readmission rates $(p<0.001)$, with a decrease in admissions for ESI $(p=0.001)$.

\section{Discussion}

This is the first comprehensive high-quality review of the surgical burden of disease at a regional level in SA that uses an in-house custom-designed electronic data-capturing tool.

\begin{tabular}{lllllll}
\multicolumn{7}{l}{ Table 1. Sex, age and length of stay by admission type } \\
\hline & Total & Burns & Elective surgery & $\begin{array}{l}\text { Non-traumatic } \\
\text { surgical emergency }\end{array}$ & Trauma & $\begin{array}{l}\text { Unplanned } \\
\text { readmission <30 days }\end{array}$ \\
\hline $\begin{array}{l}\text { Total, } N \\
\text { Patient characteristics }\end{array}$ & 9799 & 208 & 3783 & 4668 & 958 & 182 \\
$\quad$ & & & & & \\
Female, $n$ (\%) & $4152(42.2)$ & $75(36.1)$ & $1774(46.9)$ & $2070(44.3)$ & $156(16.3)$ & $77(42.3)$ \\
Male, $n$ (\%) & $5647(57.6)$ & $133(63.9)$ & $2009(53.1)$ & $2598(55.7)$ & $802(83.7)$ & $105(57.7)$ \\
Mean age, years & 43.4 & 31.7 & 47.3 & 43.3 & 31.3 & 43.5 \\
$(95 \%$ CI) & $(43.0-43.8)$ & $(29.2-34.2)$ & $(46.7-48.0)$ & $(42.7-43.9)$ & $(30.4-32.1)$ & $(40.3-46.8)$ \\
Mean length of stay, & 4.9 & 9.1 & 3.5 & 5.6 & 5.5 & 7.4 \\
days (95\% CI) & $(4.7-5.1)$ & $(7.7-10.6)$ & $(3.2-3.7)$ & $(5.3-6.0)$ & $(4.7-6.3)$ & $(5.7-9.2)$
\end{tabular}

$\mathrm{CI}=$ confidence interval. 


\begin{tabular}{|c|c|c|c|}
\hline Rank & Discharge diagnosis & NTSE admissions, $\boldsymbol{n}(\%)$ & ICD-10 code \\
\hline 1 & Appendicitis & $559(23.8)$ & K35 \\
\hline 2 & Peripheral vascular disease & $395(16.8)$ & I73.9 \\
\hline 3 & Peptic ulcer disease & $312(13.3)$ & K27 \\
\hline 4 & Abscess of skin, excluding breast and anorectal abscess & $180(7.7)$ & L02 \\
\hline 5 & Cholecystitis & $175(7.4)$ & K81.0 \\
\hline 6 & Acute pancreatitis & $162(6.9)$ & K85 \\
\hline 7 & Abdominal pain without specific cause & $153(6.5)$ & R10 \\
\hline 8 & Intestinal obstruction & $137(5.8)$ & K56.5 \\
\hline 9 & Anorectal abscess & $132(5.6)$ & K61 \\
\hline 10 & Gastritis and duodenitis & $101(4.3)$ & K29 \\
\hline 11 & Breast abscess & $95(4.0)$ & N61 \\
\hline 12 & Inguinal hernia & $87(3.7)$ & K40 \\
\hline 13 & Diabetic vasculopathy related & $66(2.8)$ & E10 \\
\hline 14 & Gallstones without cholecystitis & $66(2.8)$ & K80 \\
\hline 15 & Cancer of colon and rectum & $54(2.3)$ & $\mathrm{C} 18$ \\
\hline
\end{tabular}

\begin{tabular}{llll}
\multicolumn{4}{l}{ Table 3. Most common diagnoses of patients admitted electively for surgery or investigations $(\boldsymbol{N = 3 ~ 7 8 3 )}$} \\
\hline Rank & Discharge diagnosis & ESI admissions, $\boldsymbol{n}(\%)$ & ICD-10 code \\
\hline 1 & Gallstones & $401(23.1)$ & K80 \\
2 & Inguinal hernia & $379(21.8)$ & K40 \\
3 & Anal fistulas and fissures & $178(10.2)$ & K60 \\
4 & Ventral/umbilical hernia & $159(9.1)$ & $\mathrm{K} 42$ \\
5 & Incisional hernia & $150(8.6)$ & $\mathrm{K} 43$ \\
6 & Peripheral vascular disease & $131(7.5)$ & $\mathrm{I} 73.9$ \\
7 & Lipoma & $107(6.2)$ & $\mathrm{D} 17$ \\
8 & Cancer of the breast & $98(5.6)$ & $\mathrm{C} 50$ \\
9 & Hydrocele & $93(5.3)$ & $\mathrm{N} 43$ \\
10 & Cancer of colon and rectum & $88(5.1)$ & $\mathrm{C} 18$ \\
11 & Cancer of oesophagus & $86(4.9)$ & $\mathrm{C} 15$ \\
12 & Undescended testes & $84(4.8)$ & $\mathrm{Q} 53$ \\
13 & Varicose veins & $72(4.1)$ & $\mathrm{I} 83$ \\
14 & Cancer of prostate & $68(3.9)$ & $\mathrm{C} 61$ \\
15 & Cancer of stomach & $63(3.6)$ & $\mathrm{C} 16$
\end{tabular}

Almost half of all admissions over the 4 years were of the NTSE type, engaging the largest allocation of departmental resources. Male patients were admitted more frequently than female patients in all categories, but this difference was most marked in burn (63.9\%) and trauma $(83.7 \%)$ patients. The mean age was similar in many categories (43.3 - 47.3 years in most categories), but was lower for burns (31.7 years) and trauma (31.3 years).

Burn patients had the longest mean length of stay ( 9.1 days). Patients admitted for ESI had a length of stay of 3.5 days. The departmental practices enhanced recovery after surgery, where possible, but in many cases patient departure was delayed while waiting for government transport to their home town. The demographic and length-of-stay data were generally found to be in keeping with previously established trends.

In terms of common emergency admission diagnoses, patients with appendicitis comprised almost a quarter of all admissions. The DHSP list states that appendectomies and 'selected' laparotomies should be performed at district level. This rarely happens in practice - previous research reviewing theatre records from the 7 district facilities in this region found that only 2 facilities undertook these procedures. The volumes were low (21 appendicectomies and 6 laparotomies in 1 year) and the procedures were mostly performed by a single medical officer with a surgical interest. Acute general surgery is challenging to provide at a district hospital level acute abdominal problems requiring an operation often only reveal the diagnosis and the surgical complexity during the procedure, and doctors at these facilities are reluctant to start an operation that they cannot complete. ${ }^{[9]}$

Appendicitis, peripheral vascular disease and peptic ulcer disease comprised $>50 \%$ of the total emergency surgical admissions in our study. Some of the simpler amputations that could be managed at district level are often referred to the regional centre owing to their anaesthetic complexity. The region does have an established online referral system for endoscopy that triages patients by urgency and provides basic guidance regarding treatment.

Elective admissions also constituted $\sim 40 \%$ of total patients admitted. Patients with the top three diagnoses (gallstones, inguinal hernia and anal fistulas/fissures) contributed $55.1 \%$ of the total elective admissions. All of these patients are typically day cases in more developed countries. Worcester Hospital has a day surgery 


\begin{tabular}{llll}
\multicolumn{2}{l}{ Table $\mathbf{4}$. Most common cancer diagnoses (across all types of admission) } & $(\boldsymbol{N}=\mathbf{8 2 3})$ & \\
\hline Rank & Cancer type - diagnosis on discharge & Cancer diagnosis, $\boldsymbol{n}$ (\%) & ICD-10 code \\
\hline 1 & Colon and rectum, excluding the anus & $145(17.6)$ & C18 \\
2 & Oesophagus & $135(16.4)$ & $\mathrm{C} 15$ \\
3 & Breast & $115(14.0)$ & $\mathrm{C} 50$ \\
4 & Stomach & $109(13.2)$ & $\mathrm{C} 16$ \\
5 & Prostate & $75(9.1)$ & $\mathrm{C} 61$ \\
6 & Pancreas & $53(6.4)$ & $\mathrm{C} 25$ \\
7 & Liver and biliary tract & $25(3.0)$ & $\mathrm{C} 22$ \\
8 & Skin & $24(2.9)$ & $\mathrm{C} 44$ \\
9 & Anus & $21(2.6)$ & $\mathrm{C} 21$ \\
10 & Metastatic - primary site unknown & $17(2.1)$ & $\mathrm{C} 80$ \\
ICD-10 $=$ International Statistical Classification of Diseases and Related Health Problems - Version 10. & &
\end{tabular}

Table 5. Inhospital mortality and tertiary referral rate by admission type

\begin{tabular}{lll}
\hline Admission type & Mortality, $\boldsymbol{n}(\%)$ & Tertiary referral, $\boldsymbol{n}(\%)$ \\
\hline Burns with or without other trauma $(n=208)$ & $13(6.3)$ & $19(9.1)$ \\
Elective surgery or investigations $(n=3783)$ & $24(0.6)$ & $36(1.0)$ \\
Non-trauma surgical emergency $(n=4668)$ & $140(3.0)$ & $130(2.8)$ \\
Trauma without burns $(n=958)$ & $32(3.3)$ & $39(4.1)$ \\
Unplanned readmission in $<30$ days $(n=182)$ & $5(2.7)$ & $1(0.5)$ \\
Total $(N=9$ 799) & $214(2.2)$ & $225(2.3)$
\end{tabular}

Table 6. Admission type by year and as percentage of total admissions for year

\begin{tabular}{|c|c|c|c|c|c|}
\hline $\begin{array}{l}\text { Admission category } \\
\text { ( } p \text {-value of trend over } 4 \text { years of study using a } \\
\chi^{2} \text { test) }\end{array}$ & $\begin{array}{l}1 \text { Feb. } 2012 \text { - } \\
31 \text { Jan. } 2013 \\
\text { admissions, } n(\%)\end{array}$ & $\begin{array}{l}1 \text { Feb. } 2013 \text { - } \\
31 \text { Jan. } 2014 \\
\text { admissions, } n(\%)\end{array}$ & $\begin{array}{l}1 \text { Feb. } 2014 \text { - } \\
31 \text { Jan. } 2015 \\
\text { admissions, } \\
n(\%)\end{array}$ & $\begin{array}{l}1 \text { Feb. } 2015 \text { - } \\
31 \text { Jan. } 2016 \\
\text { admissions, } \\
n(\%)\end{array}$ & $\begin{array}{l}\text { Type over } \\
4 \text { years, } N(\%)\end{array}$ \\
\hline Burns with or without other trauma $(p=0.176)$ & $41(1.8)$ & $53(1.8)$ & $54(2.5)$ & $60(2.4)$ & $208(2.1)$ \\
\hline Elective surgery or investigations $(p=0.001)$ & $973(42.9)$ & $1160(40.4)$ & $809(37.2)$ & $841(33.9)$ & $3783(38.6)$ \\
\hline Non-trauma surgical emergency $(p=0.019)$ & $1034(45.6)$ & $1371(47.7)$ & $1045(48.1)$ & $1218(49.1)$ & $4668(47.6)$ \\
\hline Trauma without burns $(p<0.001)$ & $194(8.6)$ & $248(8.6)$ & $213(9.8)$ & $303(12.2)$ & $958(9.8)$ \\
\hline Unplanned readmission in $<30$ days $(p<0.001)$ & $27(1.2)$ & $41(1.4)$ & $53(2.4)$ & $61(2.5)$ & $182(1.9)$ \\
\hline Admissions for year, $N$ & 2269 & 2873 & 2174 & 2483 & 9799 \\
\hline
\end{tabular}

ward, but staff and patient transport service limitations prevent it being used to its full extent. Expansion of the transport service might improve day-case capacity and free up beds that are blocked by patients awaiting transport home.

Inguinal and umbilical hernia repair, hydrocelectomy and orchidectomy are on the DHSP list, and an argument may be made for extending outreach programmes so that these are performed at district level, either by expansion of the surgical and anaesthetic specialist cover, or by training doctors at these facilities to perform the procedures unsupervised. Many doctors perform their community service at a district level hospital and are therefore at the facility for only 12 months, which makes setting up an effective teaching programme more challenging.

A total of 823 (8.4\%) of all patients admitted during the study were diagnosed with cancer. Data on prevalence of cancers and commonly occurring diagnoses may be used for future studies in this facility or to compare with those of other regions or tertiary centres.

Mortality rates for burns (6.3\%) and trauma (3.3\%) are higher than those for other categories of admission. Both conditions have been conclusively shown to benefit from early treatment in the region served by our facility. As is the case in many regional facilities in SA, the large distances between the site of injury and the definitive treatment centre, combined with a limited ambulance service, is a significant factor.
Tertiary referral was also most common for burns (9.1\%) and trauma (4.1\%). The lack of availability of CT scanning facilities after hours and the absence of critical care unit beds make management of these patients particularly challenging and might contribute to the higher referral rates. Increasing the availability of imaging and critical care might allow some of the patients to be managed at a regional level.

Readmission rates within 30 days are according to accepted norms. ${ }^{[15]}$

The statistically significant increase in NTSE admissions, trauma and readmissions in $<30$ days, as well as the decrease in elective cases observed over the study period, was noted, and has also been seen anecdotally by the department, which is required to cancel elective cases with increasing frequency.

Regional hospital surgical bed numbers are either fixed or decreasing. This limited capacity must be stretched to manage a greater number of ageing patients with diseases of lifestyle, whose demands for more complex surgical care are higher and whose illnesses are often at a more advanced pathological stage than regional centres internationally. Clarke et al. ${ }^{[16]}$ demonstrated this by comparing data on appendicectomy at Edendale Hospital, Pietermaritzburg, SA, with those of other countries and showed higher complication rates in $\mathrm{SA}$, indicating dysfunction of the system overall. Further data from regional level are urgently needed to validate more accurately the concerning trend of the current situation, to argue for reallocation 
of funding, as well as to measure improvement. As electronic health records are developed and deployed, such data might be more readily available.

In a study using discharge summaries as an information source, accurate data input is essential to ensure the quality of research. Error is present where suboptimal ICD-10 codes have been selected - this phenomenon is well described. ${ }^{[17]} \mathrm{A}$ strength of this study is that all entered data are the responsibility of the attending medical doctors and not of administrative staff. Ongoing training of medical staff regarding the importance of accurate ICD-10 coding and increased consultant supervision have led to improvement in the quality of ICD-10 coding over the study period.

\section{Study limitations}

Identified weaknesses in this study were ensuring inclusion of all patients who died or were referred to a tertiary centre, and accurate ICD-10 coding for burn and trauma admissions. For the latter, mechanism and surface area codes were used interchangeably with injury and burn depth codes in the early years of the database. This error was identified and corrected going forward, but the data were insufficient for inclusion. Another weakness was that the analysis of admission trends was performed using a relatively simple method, and was not adjusted for confounding variables.

The National Department of Health should be encouraged to develop their intention ${ }^{[12]}$ of improving access to safe surgery and anaesthesia. Improvements specific to this region could include expansion of the outreach service to provide more specialist care and teaching at district level, better patient transport services and daysurgery capacity at regional level, and ensuring that budget allocation is proportional to where surgical care is delivered. Further studies at regional and district level will inform more accurate planning.

\section{Conclusion}

This study provides a description of the surgical burden of disease at an SA regional hospital as well as a starting point for evaluating admission trends over time in this region, and could prove a useful comparator for similar studies in other regions.

A precise understanding of disease profile is essential for effective budgeting and resource allocation. Ongoing surveillance such as that performed in our study provides this critical information and should be prioritised to measure capacity and efficacy of the surgical service at both regional and district levels, and to plan for improvement.

Declaration. None.

\section{Acknowledgements. None.}

Author contributions. JP: literature review, analysis of data, write-up of article; OS: design, statistical analysis, review, critical revision and approval; RD: creation and implementation of database, extraction of data, review, critical revision and approval.

Funding. None.

Conflicts of interest. None.

1. Schuurman N, Cinnamon J, Walker BB, et al. Intentional injury and violence in Cape Town, South Africa: An epidemiological analysis of trauma admissions data. Glob Health Action 2015;8:27016. https://doi.org/10.3402/gha.v8.27016

2. Kong VY, Bulajic B, Allorto NL, Handley J, Clarke DL. Acute appendicitis in a developing country. World J Surg 2012;36(9):2068-2073. https://doi.org/10.1007/s00268-012-1626-9

3. Stewart B, Khanduri P, McCord C, et al. Global disease burden of conditions requiring emergency surgery. Br J Surg 2014;101(1):9-22. https://doi.org/10.1002/bjs.9329

4. Campbell WB, Lee EJK, van de Sijpe K, Gooding J, Cooper MJ. A 25-year study of emergency surgical admissions. Ann R Coll Surg Engl 2002;84(4):273-277.

5. Naidoo S. The South African national health insurance: A revolution in health-care delivery! J Public Health 2012;34(1):149-150. https://doi.org/10.1093/pubmed/fds008

6. Ataguba JE-O, Akazili J. Health care financing in South Africa: Moving towards universal coverage. CME 2010;28(2):74.

7. National Department of Health. The District Health System in South Africa: Progress Made and Next Steps. Pretoria: NDoH, 2001.

. National Department of Health. A District Hospital Service Package for South Africa. Pretoria: NDoH, 2002.

9. Voss M, Duvenage R. Operative surgery at the district hospital. S Afr Med J 2011;101(8):521-522.

10. Shrime MG, Bickler SW, Alkire BC, Mock C. Global burden of surgical disease: An estimation from the provider perspective. Lancet Glob Health 2015;3(Suppl 2):S8-S9. https://doi.org/10.1016/S2214the provider persp
$109 \mathrm{X}(14) 70384-5$

11. Daar AS, Singer PA, Persad DL, et al. Grand challenges in chronic non-communicable diseases. Nature 2007;450(7169):494-496. https://doi.org/10.1038/450494a

12. Patel N, Peffer M, Leusink A, Singh N, Smith M. Surgery and anaesthesia in the South African context:

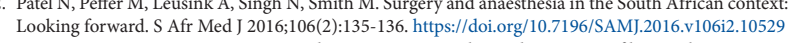
Western Cape Government. Provincial Treasury Regional Development Profile Overberg Distric 2013 Working Paper. Cape Town: Western Cape Government, 2013. http://www.westerncape.gov.za

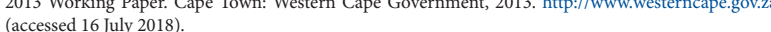

Wested

4. Western Cape Government. Provincial Treasury Regional Development Profile Cape Winelands District 2013 Working Paper. Cape Town: Western Cape Government, 2013. http://www.westerncape. gov.za (accessed 16 July 2018)

5. Kassin MT, Owen RM, Perez SD, et al. Risk factors for 30-day hospital readmission among general surgery patients. J Am Coll Surg 2012;215(3):322-330. https://doi.org/10.1016/j.jamcollsurg.

6. Clarke DL, Kong VY, Handley J, Aldous C. A concept paper: Using the outcomes of common surgical conditions as quality metrics to benchmark district surgical services in South Africa as part of a systematic quality improvement programme. S Afr J Surg 2013;51(3):84. https://doi.org/10.7196 SAJS. 1476

17. Burns EM, Rigby E, Mamidanna R, et al. Systematic review of discharge coding accuracy. J Public Health 2012;34(1):138-148. https://doi.org/10.1093/pubmed/fdr054

Accepted 13 August 2018. 